\title{
Global scale analysis and modelling of primary microseisms
}

\author{
L. Gualtieri ${ }^{\odot},{ }^{1}$ E. Stutzmann, ${ }^{2}$ C. Juretzek, ${ }^{3,4}$ C. Hadziioannou ${ }^{3}$ and F. Ardhuin ${ }^{5}$ \\ ${ }^{1}$ Department of Geosciences, Princeton University, Guyot Hall, Princeton, NJ 08540, USA. E-mail: luciag@princeton.edu \\ ${ }^{2}$ Institut de Physique du Globe de Paris, 1 Rue Jussieu, 75005 Paris, France \\ ${ }^{3}$ Institute of Geophysics, Center for Earth System Research and Sustainability (CEN), Universität Hamburg, D-20146 Hamburg, Germany \\ ${ }^{4}$ Department of Earth and Environmental Sciences, Ludwig Maximilian University of Munich, D-80333 Munich, Germany \\ ${ }^{5}$ Univ. Brest, CNRS, Ifremer, IRD, Laboratoire d'Océanographie Physique et Spatiale (LOPS), IUEM, Brest, 29280, France
}

Accepted 2019 March 27. Received 2019 March 20; in original form 2018 September 14

\begin{abstract}
S UMMAR Y
Primary microseism is the less studied seismic background vibration of the Earth. Evidence points to sources caused by ocean gravity waves coupling with the seafloor topography. As a result, these sources should be in water depth smaller than the wavelength of ocean waves. Using a state-of-the-art ocean wave model, we carry out the first global-scale seismic modelling of the vertical-component power spectral density of primary microseisms. Our modelling allows us to infer that the observed weak seasonality of primary microseisms in the southern hemisphere corresponds to a weak local seasonality of the sources. Moreover, a systematic analysis of the source regions that mostly contribute to each station reveals that stations on both the east and west sides of the North Atlantic Ocean are sensitive to frequencydependent source regions. At low frequency (i.e. $0.05 \mathrm{~Hz}$ ), the dominant source regions can be located thousands of kilometres away from the stations. This observation suggests that identifying the source regions of primary microseisms at the closest coasts can be misleading.
\end{abstract}

Key words: Numerical modelling; Computational seismology; Seismic noise; Theoretical Seismology.

\section{INTRODUCTION}

Ambient seismic noise recorded worldwide between about 0.05 and $0.08 \mathrm{~Hz}$ is called primary microseism, and it can be generated by ocean gravity waves propagating over the seafloor in shallow water (Hasselmann 1963). Seismic waves have the same frequency as ocean waves, and therefore primary microseisms are sometimes called single-frequency microseisms. While ambient seismic noise at higher frequencies (secondary microseisms) and lower frequencies (seismic 'hum') has been widely studied, very little has been done about primary microseisms.

Early studies identified sources of primary microseisms in nearshore regions by comparing spectra of microseisms and swells (e.g. Haubrich et al. 1963) or by frequency-wavenumber analysis (e.g. Haubrich \& McCamy 1969; Cessaro 1994). More recent studies also used beamforming analysis to infer the location of the sources of Rayleigh and Love waves in the primary microseism frequency band (e.g. Juretzek \& Hadziioannou 2016, 2017; Gal et al. 2018). Primary microseisms recorded on the vertical-component seismograms are dominated by the fundamental mode of Rayleigh waves (e.g. Haubrich \& McCamy 1969; Schimmel et al. 2011). The energy ratio between Rayleigh and Love waves on the horizontal components is still under debate and may vary with the location of the seismic station (e.g. Friedrich et al. 1998; Nishida et al. 2008;
Juretzek \& Hadziioannou 2017). Several of these studies were conducted assuming that the coast responsible for the generation of primary microseisms was the closest one along the source-receiver direction obtained by beamforming analysis.

The coupling of surface gravity waves and seafloor topography simplifies in the case of a constant slope (Hasselmann 1963) or a fine-scale random topography (Ardhuin 2018). Using the first approach extended to slowly varying topography, Ardhuin et al. (2015) modelled the amplitude of the vertical-component primary microseisms. They showed that the power spectral density (PSD) of primary microseisms could be well modelled at three stations in Europe considering sources in shallow water close to the oceancontinent boundary, and assuming a constant ocean-bottom slope and a uniform ocean floor topography along the coast. In that case, ocean waves can be considered to be perpendicular to the topography. Therefore, in agreement with previous theoretical studies (e.g. Hasselmann 1963; Saito 2010), they considered ocean waves perpendicular to the topography in shallow water as the main factor responsible for the generation of primary microseism. Small deviations from the perpendicular direction due to 3-D topographic effects were not taken into account.

In this paper, we perform the analysis and modelling of $1 \mathrm{yr}$ of continuous seismic data recorded on the vertical component of 24 seismic stations of the Geoscope network located worldwide. We focus on frequencies between 0.05 and $0.08 \mathrm{~Hz}$. In Section 2 
we describe the analysis workflow applied to our seismic data set and we detail the method used for modelling seismic PSDs. In Section 3, we show maps of sources of primary microseisms, and we compare our modelling with observations as a function of time and frequency. We also locate the sources that mostly contribute to primary microseisms at each station by inferring the source region that on its own can explain the spectrum of primary microseisms. To assess the robustness of our approach, in Appendix A we present the modelling of another year of data using the same method discussed in Section 2.

\section{DATA AND METHOD}

We analyse vertical continuous seismic data recorded at 24 seismic stations (triangles in Fig. 2) of the Geoscope network in 2013. We use the vertical-component long-period (LHZ) seismograms, with a sampling rate of $1 \mathrm{~Hz}$. The instrumental response is deconvolved from raw seismograms in order to get ground displacement, and the PSD (in $\mathrm{dB}$ with respect to $1 \mathrm{~m}^{2} \mathrm{~Hz}^{-1}$ ) is computed every 3 $\mathrm{hr}$, considering $50 \%$ overlapping time windows of $1024 \mathrm{~s}$. To avoid earthquakes and retain only ambient seismic noise, we keep the minimum value of the PSD every $24 \mathrm{hr}$.

We model the vertical-component PSD at the same 24 seismic stations, following the theoretical framework proposed by Hasselmann (1963) and Ardhuin et al. (2015). To evaluate the location and amplitude of the sources, we use the numerical ocean wave model WAVEWATCH III, version 5.12, as implemented by Ardhuin et al. (2014) with output available at ftp://ftp.ifremer.fr/ifrem er/ww3/HINDCAST. The model is forced by winds from the European Center for Medium-Range Weather Forecast (ECMWF) every $3 \mathrm{hr}$. Extended sources are discretized in a grid of point sources each $0.5^{\circ}$ both in latitude and in longitude. The amplitude of the sources is expressed as pressure PSD induced by ocean waves propagating over the seafloor. The ocean wave spectrum is evaluated along the shorelines, and only waves in the direction perpendicular to the shore - both towards and away from the shore - are taken into account (Ardhuin et al. 2015). Following Hasselmann (1963), we do not consider shallow depths that have no nearby coastline.

The simplified model of Ardhuin et al. (2015) based on a largescale sloping seafloor may require unrealistic large bottom slopes where small-scale topographic features (with wavelengths similar to those of ocean waves, typically $50-500 \mathrm{~m}$ ) have large amplitudes (Ardhuin 2018). The coupling between these topographic features and ocean waves along the perpendicular direction is a possible source of primary microseisms. However, these features are not generally known, making it impossible to take them into account at the global scale. In general, the energy level of ocean waves in directions perpendicular to shore is highly correlated to the energy in other directions so that the theoretical sources used here are a good proxy for general sources caused by all types of bottom topographies. The detailed expression of the pressure PSD $F_{p}(f)\left[\mathrm{Pa}^{2} \mathrm{~m}^{2} \mathrm{~s}\right]$ at the seafloor is given by Ardhuin et al. (2015) (Supporting Information eq. S22) and by Ardhuin et al. (2019) (eq.3.16).

In that theoretical model, the source PSD is proportional to an effective slope, called $s$ in Ardhuin et al. (2015) (expressed in percentage form) and in Ardhuin et al. (2019) (expressed in decimal form), which is not well known in the frequency band of primary microseisms due to uncertainties on bottom topography at scales under $5 \mathrm{~km}$. However, as we shall see in the following, our first-order modelling of primary microseisms does not take into account local site effects at the source [e.g. sediments (e.g. Gualtieri et al. 2015; Koper
\& Burlacu 2015), fine-scale seafloor roughness (e.g. Ardhuin 2018)] and 3-D propagation effects [e.g. scattering at the ocean-continent boundary, focusing and defocusing at heterogeneities (e.g. Ziane \& Hadziioannou 2019)]. Both of these aspects are not negligible at the frequencies of primary microseisms. Therefore, we define an effective fitting parameter $\gamma$ (expressed in percentage form), which accounts for effects that are not known [e.g. large-scale bathymetric effects, that is the slope factor $s$ of Ardhuin et al. (2015) and Ardhuin et al. (2019), and small-scale topographic effects as in Ardhuin (2018)] or not taken into account in our modelling (source-site and 3-D propagation effects). We point out that our effective fitting parameter $\gamma$ weakly varies with frequency and therefore can be assumed constant (see Section 3.4 for a more detailed explanation). This assumption is justified by the fact that we consider a narrow frequency band $(0.05-0.08 \mathrm{~Hz})$ and, as we will see in the next section, the spectrum of primary microseisms expressed in displacement varies within a few $\mathrm{dB}$ over this frequency band.

A pressure source acting over a given surface at the ocean seafloor in shallow water is equivalent to a vertical force applied on a flat Earth surface. Assuming a homogeneous half-space, the verticalcomponent PSD of the total displacement $u(f)\left[\mathrm{m}^{2} \mathrm{~Hz}^{-1}\right]$ recorded at a seismic station at a given time can be written as the integral over the displacement PSDs due to each vertical point force (e.g. Kanamori \& Given 1981):

$$
\begin{aligned}
u(f)= & \gamma \int_{0}^{2 \pi} \int_{0}^{\pi} \frac{(2 \pi)^{2} f c^{2}}{\rho_{\mathrm{c}}^{2} \beta_{\mathrm{c}}^{5}} \\
& \times F_{\mathrm{p}}(f)\left[\frac{\mathrm{e}^{-\frac{\omega \Delta R}{Q(f) U(f)}}}{R \sin \Delta}\right] R^{2} \sin \phi \mathrm{d} \lambda \mathrm{d} \phi
\end{aligned}
$$

where $f$ is the seismic frequency, $\rho_{c}=2600 \mathrm{~kg} \mathrm{~m}^{-3}$ is the density of the crust, $\beta_{c}=2.8 \mathrm{~km} \mathrm{~s}^{-1}$ is the $S$-wave velocity in the crust, $R=6371 \mathrm{~km}$ is the radius of the Earth, $\Delta$ is the spherical distance between source and receiver, and $\lambda$ and $\phi$ are the longitude and colatitude of the sources, respectively. The adimensional coefficient $c$ accounts for the (resonance) site effect due to the ocean depth at the source (Longuet-Higgins 1950). We observe that at frequencies between 0.05 and $0.08 \mathrm{~Hz}$ and in shallow water, where the sources of primary microseisms are located (Ardhuin et al. 2015), the coefficient $c$ is only relevant to the fundamental mode of Rayleigh waves ( $c_{1}$ in Longuet-Higgins 1950, his fig. 1) and it is nearly constant with frequency and ocean depth (unlike for secondary microseisms, e.g. Gualtieri et al. 2013). Therefore, the coefficient $c$ in our computation is set to the corresponding constant value, $c \simeq 0.2$. The attenuation $Q(f)$ and the group velocity $U(f)$ are computed for the fundamental mode of Rayleigh waves in the frequency band $0.05-0.08 \mathrm{~Hz}$ using the QL6 model (Durek \& Ekström 1996) and the continental version of the Preliminary Reference Earth Model (PREM) model (Dziewonski \& Anderson 1981), respectively. The term $e^{-\frac{\omega \Delta R}{Q(f) U(f)}}$ accounts for minor-arc propagation. At the frequencies of primary microseisms, major-arc and multiorbit propagation can be neglected.

As already discussed, the displacement PSD $u(f)$ depends on the value of the effective fitting parameter $\gamma$, which includes effects due to the slope of the seafloor over which ocean waves propagate, as well as local source site effects and propagation effects. While the latter aspects are not included in our first-order modelling, the bathymetric and slope effects are unknown for two main reasons. 

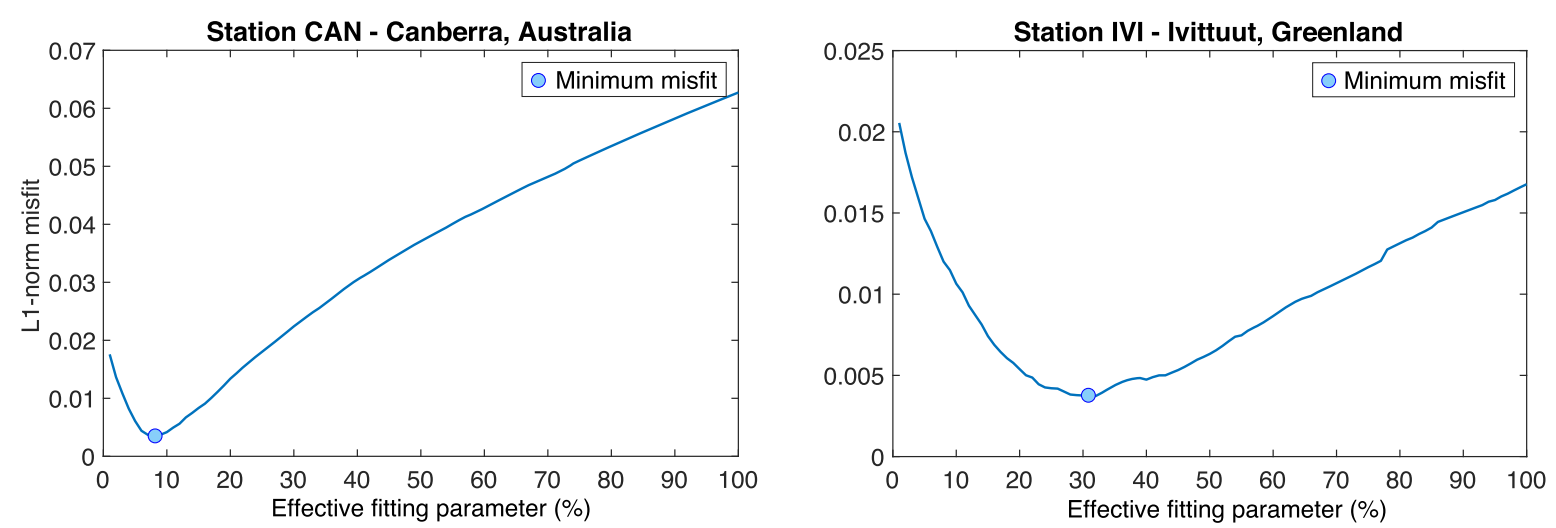

Figure 1. L1-norm misfit between observed and modelled PSDs as a function of the effective fitting parameter $\gamma$ for stations a) CAN (Canberra, Australia) and b) IVI (Ivittuut, Greenland). The blue dot in each panel highlights the value of the effective fitting parameter $\gamma$ at which the misfit is minimum.

First, the source magnitude is the result of a complex interference between surface ocean waves and the bottom topography. Second, the ocean floor geometry is generally not known to a level of detail sufficient to estimate the contribution of the slope or the fine-scale bathymetric roughnesses to $\gamma$. Therefore, to achieve the first-order modelling of primary microseisms, we estimate an effective fitting parameter $\gamma$ for each station minimizing the L1 norm between $1 \mathrm{yr}$ of observed and synthetic PSDs, considering their minimum value every $24 \mathrm{hr}$. Fig. 1 shows two examples of the misfit as a function of the effective fitting parameter $\gamma$ for stations (a) CAN (Canberra, Australia) and (b) IVI (Ivittuut, Greenland). The minimum misfit (blue dot) is clearly identified in both cases.

Assessing an effective fitting parameter $\gamma$ for each station allows us to perform the first-order modelling of primary microseisms. This parameter includes both local and propagation effects, which cannot be distinguished with the present first-order modelling. In the following section, we will discuss the main outcomes of our modelling. We will also present a strategy to refine the estimate of the effective fitting parameter by inverting for fitting parameters that vary with a given source area.

\section{RESULTS}

\subsection{Worldwide modelling}

In Fig. 2, we show a map of the median pressure PSD of primary microseisms. The value of the PSD of each source is the median value over 2013 and in the frequency band $0.05-0.08 \mathrm{~Hz}$. We observe that sources on the eastern side of ocean basins at mid-latitudes (i.e. western coasts of Europe and the US) are stronger than sources on the western side. This evidence is due to the prevalence of westerly winds at mid-latitudes. We also observe that many small islands worldwide are associated with sources of primary microseisms.

A few observations of sources of primary microseisms have been documented in the literature by triangulation of azimuths to the incoming waves. For example, Cessaro (1994) observed persistent primary microseism sources in the North Pacific Ocean near the west coast of the Queen Charlotte Islands (Canada) and the North Atlantic Ocean near the coast of Newfoundland (Canada). In both these regions, the pressure PSD computed from the ocean wave model (Fig. 2) shows a large amplitude.

The surrounding insets in Fig. 2 show the PSD (in $\mathrm{dB}$ with respect to $1 \mathrm{~m}^{2} \mathrm{~Hz}^{-1}$ ) as the median over the PSDs computed every $3 \mathrm{hr}$ in 2013 and as a function of frequency. In the case of missing data, we consider only the portion of synthetics for which we have data. Data are in blue and synthetics in red. Overall, synthetic and observed PSDs have the same amplitude, shape, and slope. The fit between data and synthetics is within a few $\mathrm{dB}$, up to a maximum error of about $4 \mathrm{~dB}$ at the station PPTF in French Polynesia.

Each synthetic PSD is computed by searching the value of the effective fitting parameter $\gamma$ that minimizes the L1 norm between continuous observed and synthetic records averaged between 0.05 and $0.08 \mathrm{~Hz}$ over the year 2013. The effective fitting parameter $\gamma$ for each station is shown in Fig. 3 (colour scale) and listed in Supporting Information Table S1. Being affected by source (e.g. local site effects due to sediments and fine-scale seafloor roughness) and propagation effects (e.g. scattering at the ocean-continent boundary, focusing and defocusing at heterogeneities), other than by the slope of the bathymetry at the coast, the effective fitting parameter $\gamma$ in Fig. 3 does not present a simple geographical pattern. However, we can observe small values of $\gamma$ at stations surrounding the Pacific Ocean (blue triangles) and large values in Europe and Africa (green triangles). A more complex pattern can be observed at seismic stations in the Indian Ocean, where $\gamma$ is characterized by a large range of values. The effective fitting parameter has an order of magnitude of 10 and it is always larger than 1 . This means that the features that we do not take into account in our modelling (see Section 2) contribute to the PSD recorded at the seismic stations. In Appendix A, we show that these effective fitting parameters estimated using data in 2013 are time independent, and they allow us to model another year of data.

\subsection{Seasonal variations}

In Fig. 4, we investigate the seasonality of primary microseisms. Figs 4(a) and (b) show maps of primary microseism sources in January and July 2013, respectively. Sources are defined as the median pressure PSD between 0.05 and $0.08 \mathrm{~Hz}$. In the Northern Hemisphere, sources are stronger during the local winter (January, Fig. 4a) than during the local summer (July, Fig. 4b), notably on both east and west sides of the North Atlantic Ocean, on the coasts of Greenland and the Mediterranean Sea. Weaker variability is observed on both sides of the North Pacific Ocean. In the southern hemisphere, seasonal variability is less pronounced, with only some confined regions (e.g. Pacific coasts of South America) clearly showing stronger sources during the southern hemisphere winter (July, Fig. 4b). The amplitude of sources around Antarctica varies in response to local effects, such as the presence of sea ice, and 

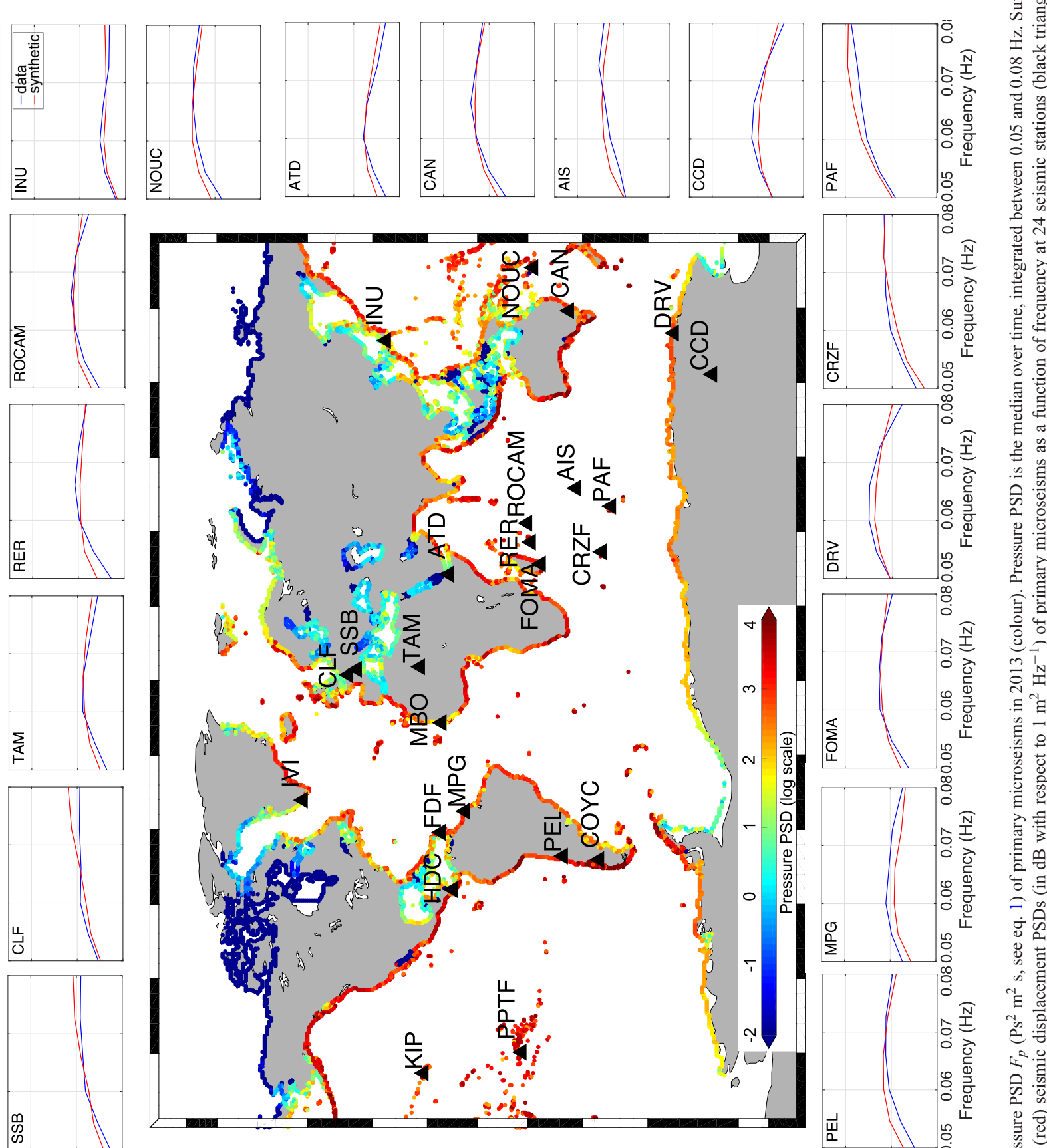

을

․․․

क

.




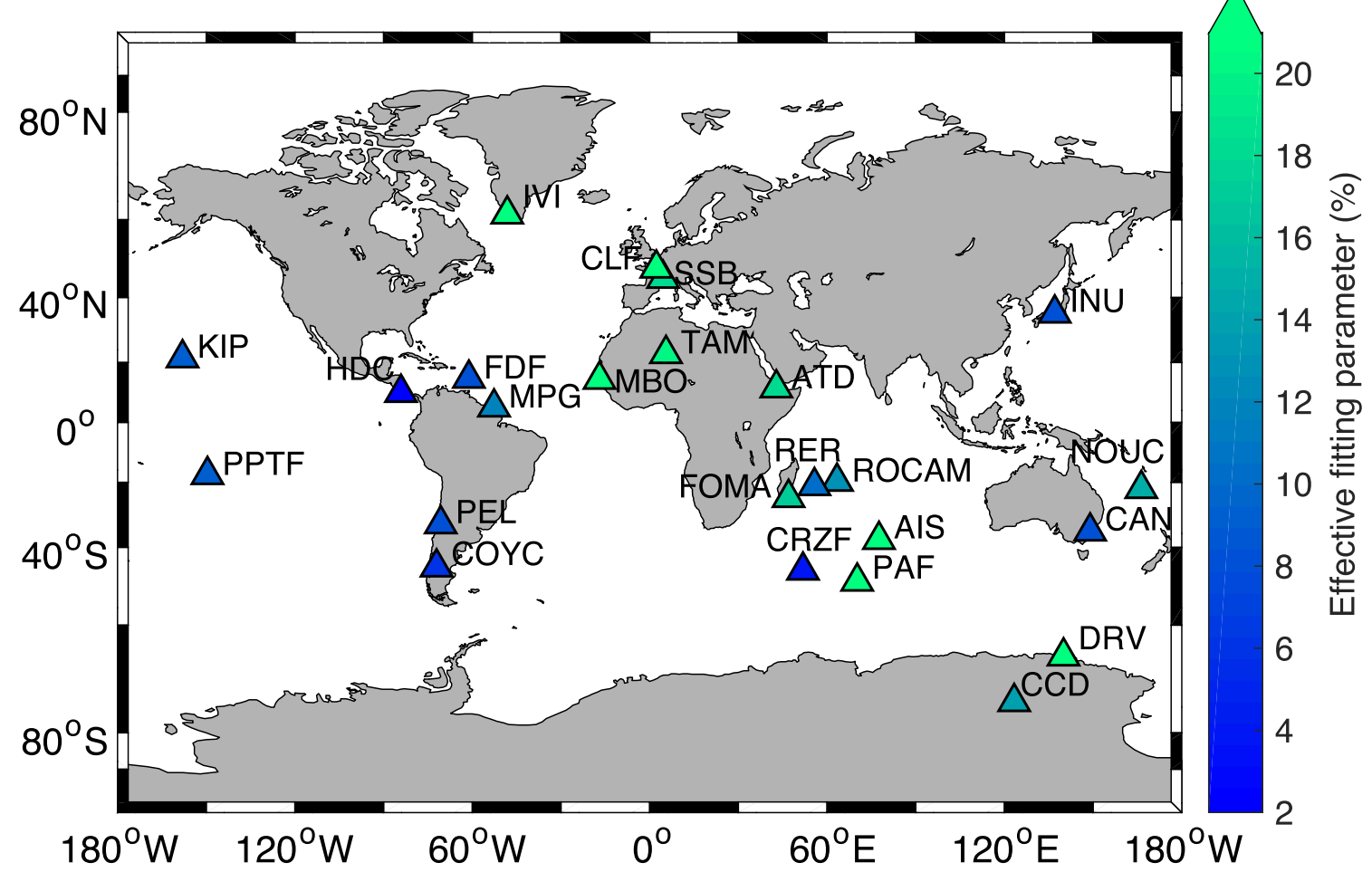

Figure 3. Map showing the effective fitting parameter $\gamma$ resulting from the L1-norm misfit minimization between observed and synthetic PSDs.

(a)

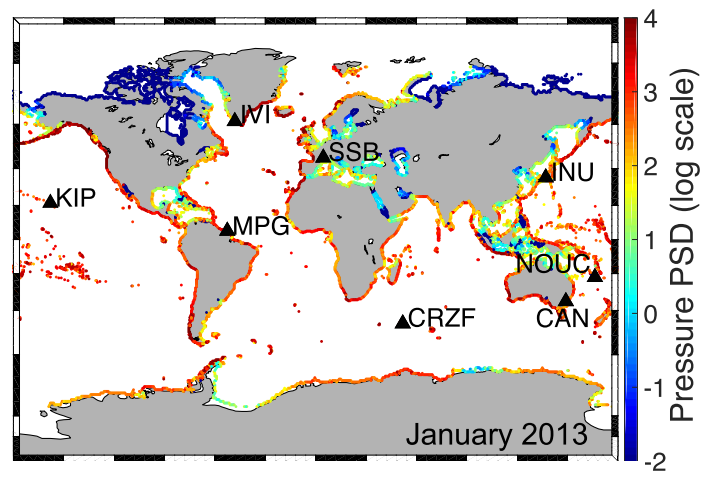

(b)

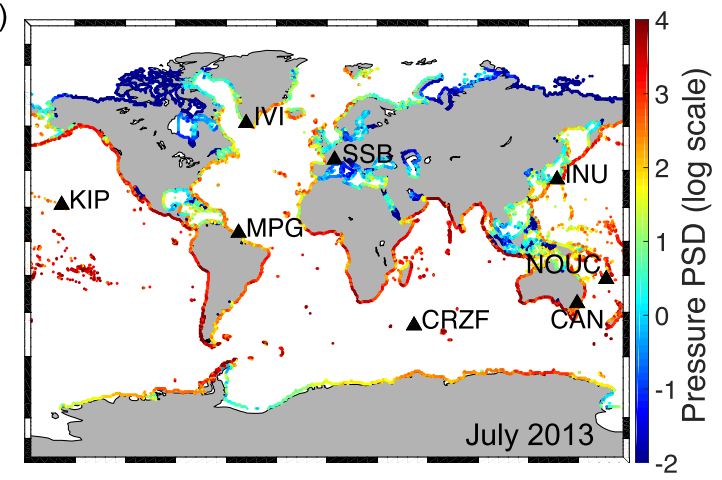

(c) 80

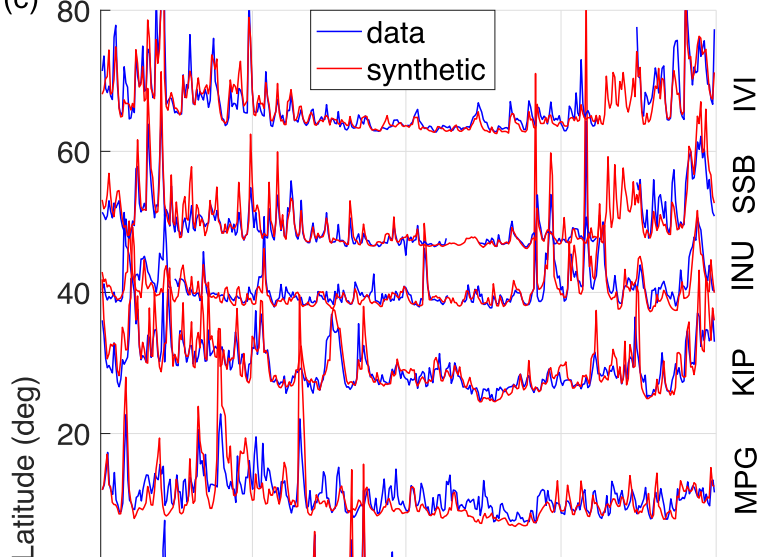

$$
0
$$

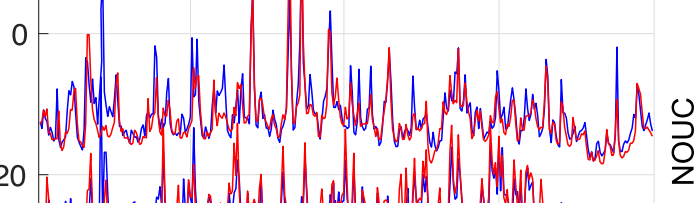

$-20$

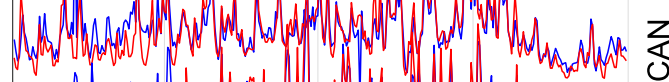

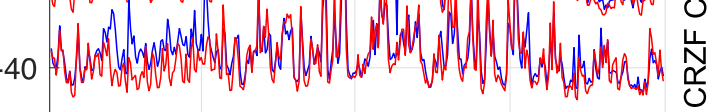

$$
\text { Jan Apr } \quad \text { Jul } \quad \text { Oct Jan }
$$

Figure 4. Pressure PSD $F_{\mathrm{p}}\left(\mathrm{Ps}^{2} \mathrm{~m}^{2} \mathrm{~s}\right)$ of primary microseisms as the median over time and frequency in (a) January 2013 and (b) July 2013 . (c) Observed (blue) and synthetic (red) seismic displacements in 2013 at eight seismic stations (triangles in panels a and b) as a function of time ( $x$-axis). The time-series are normalized with respect to the standard deviation at each station and sorted by station latitude ( $y$-axis) to enhance seasonal patterns on both hemispheres. To avoid earthquake signals, we keep the minimum value every $24 \mathrm{hr}$ in both data and synthetics. Major peaks and seasonality are well modelled. 
therefore does not follow a regular seasonal variability, as also observed for secondary microseisms (e.g. Stutzmann et al. 2009; Grob et al. 2011; Stutzmann et al. 2012). A peculiar case is represented by the sources along the coasts of India. Despite being located on the Northern Hemisphere, they show a larger amplitude in July than in January. As already observed for secondary microseisms (e.g. Koper \& de Foy 2008; Stutzmann et al. 2012; Davy et al. 2015), the sources around India experience a strong seasonality typical of the southern hemisphere.

The seasonality of the sources is reflected in the seasonality of the recorded primary microseisms. Fig. 4(c) shows time-series of RMS minimum displacement integrated over the $0.05-0.08 \mathrm{~Hz}$ frequency band. We keep the minimum value every $24 \mathrm{hr}$ to remove earthquake signals. The time-series are plotted as a function of the latitude of the stations ( $y$-axis). The time evolution of data (blue) and synthetics (red) is in good agreement, and many strong peaks are well reproduced by our modelling. Moreover, the grounddisplacement time-series show a pronounced seasonal variability, especially at stations in the Northern Hemisphere, where the amplitude of the primary microseism ground displacement is larger in January-February than in July-August. Stations in the southern hemisphere exhibit less seasonal variability_although we still observe higher ground-displacement in January-February than in July-August - in agreement with the time-varying behaviour of the source amplitude in the southern hemisphere. A similar seasonality can be observed in 2017 (see Appendix A, Fig. A1a). This evidence is in agreement with observations at the global scale by Schimmel et al. (2011) and in the Indian Ocean by Stutzmann et al. (2009) and Davy et al. (2015), who showed weak seasonal variations of primary microseisms and pronounced seasonal variations of secondary microseisms. The high periodicity of secondary microseisms in the southern hemisphere was also observed in Australia by Aster et al. (2008) using a quantitative metric to asses seasonality over two decades and by Schimmel et al. (2011) by computing the backazimuth to the incoming waves over $8 \mathrm{yr}$.

\subsection{Dominant source regions}

To understand where primary microseisms recorded at each station come from, we perform simulations considering subsets of the sources. We divide the global-scale source distribution into 12 regions, as shown in Fig. 5. Then we model the amplitude of the spectrum and the time evolution of the ground displacement considering each one of these source subregions separately. For each station, we use the same effective fitting parameter $\gamma$ used for the global-scale simulations (Supporting Information Table S1). In such a way, a direct comparison with the global-scale simulations can be performed. Triangles in Fig. 5 denote seismic stations, and their colour reflects the dominant source region. Triangles showing two colours indicate stations where primary microseisms are due to two different source regions.

Fig. 6 shows the median PSD in 2013 (Fig. 6a) and the time evolution of the RMS displacement at $0.08 \mathrm{~Hz}$ (Fig. 6b) and $0.05 \mathrm{~Hz}$ (Fig. 6c) at the station CAN (Canberra, Australia). Fig. 7 shows the same quantities at the station IVI (Ivittuut, Greenland). The colour of the solid lines reflects the source subregion (Fig. 5) used to compute the synthetic spectra and RMS minimum displacement. Dashed lines denote data (blue) and synthetics computed considering the global-scale distribution of sources (red).

At the station CAN (Fig. 6a), sources from all around Australia (black line) dominate at all frequencies, while the contribution of the other regions decreases with distance. This occurs all year round, as shown in Fig. 6(b) at frequency $f=0.08 \mathrm{~Hz}$, and in Fig. 6(c) at frequency $f=0.05 \mathrm{~Hz}$. We observe that the fit is particularly good at $f=0.08 \mathrm{~Hz}$, while at $f=0.05 \mathrm{~Hz}$ the modelled time-series of RMS minimum displacement (dashed red line) shows larger amplitudes than observations (blue dashed line), especially during the local winter. The same observation can be made for 2017 (see Appendix A, Fig. A2). Detailed investigation of this evidence can be found in Section 3.4.

At IVI (Fig. 7a), the dominant source region is frequency dependent: sources around Greenland (yellow) give the largest contribution at $f>0.06 \mathrm{~Hz}$, and sources on the west coasts of North America dominate at $f<0.06 \mathrm{~Hz}$. Although the sources along the east coast of North America (dark red) are located closer to the station IVI, they give a smaller contribution. The time-series of RMS minimum displacement at $f=0.08 \mathrm{~Hz}$ (Fig. 7b) due to sources around Greenland (yellow) is the largest contribution throughout the year, with some sporadic dominant contributions due to sources around Europe (e.g. in April). At $f=0.05 \mathrm{~Hz}$ (Fig. 7c), the contribution due to sources on the western (Pacific) coasts of North America (distance beyond $2800 \mathrm{~km}$ ) is the largest on average, although several individual peaks are due to sources around Greenland (e.g. in May), and Europe (e.g. in November).

Primary microseisms at about $83 \%$ of the stations can be explained by a unique source region at all frequencies (colour of triangles in Fig. 5a and spectra in Supporting Information Figs S1-S4). Some stations are located in the middle of their dominant source regions (e.g. INU in Japan, TAM in Algeria, KIP and NOUC on islands in the Pacific Ocean), while some others are located close to edge of their dominant source regions (e.g. HDC in Costa Rica, AIS, PAF and CRZF on islands in the Indian Ocean).

On the other hand, primary microseisms at about $17 \%$ of the stations-FDF and MPG along the eastern coasts of the central Atlantic, IVI in Greenland, CLF and SSB in France-are characterized by two main dominant source regions for varying frequency (triangles showing two colours in Fig. 5 and spectra in Supporting Information Fig. S4). Some of the stations are characterized by adjacent dominant source regions: SSB and CLF in France where the dominant source regions are Europe and Africa. Primary microseisms at stations in Antarctica, CCD and DRV, show instead dominant sources located around Australia. Some other stations are characterized by local and distant source regions: IVI in Greenland where the dominant source regions are Greenland and the coasts of northwest America, and FDF and MPG along the eastern central Atlantic coasts where the dominant source regions are southeast and southwest America. At high frequency $(f \simeq 0.08 \mathrm{~Hz}$ ), the closest subregion always dominates, while at low frequency $(f \simeq 0.05 \mathrm{~Hz})$, it is the subregion located further away that dominates (see Fig. 7a and Supporting Information Fig. S4). Notably, at low frequency ( $f$ $\simeq 0.05 \mathrm{~Hz}$ ), the dominant source region is located beyond about: $2000 \mathrm{~km}$ from the station FDF, $2750 \mathrm{~km}$ from MPG, $1220 \mathrm{~km}$ from CLF, $880 \mathrm{~km}$ from SSB, and $2820 \mathrm{~km}$ from IVI. This evidence demonstrates that primary microseisms recorded at a seismic station can also be generated at distant coasts, especially around $0.05 \mathrm{~Hz}$.

\subsection{Source-dependent effective fitting parameter}

In our computations, a constant effective fitting parameter $\gamma$ has been used for simulating synthetic PSDs at each seismic station. The effective fitting parameter is defined as the value that minimizes the misfit between data and synthetics. In Figs 6 and 7, we observed 


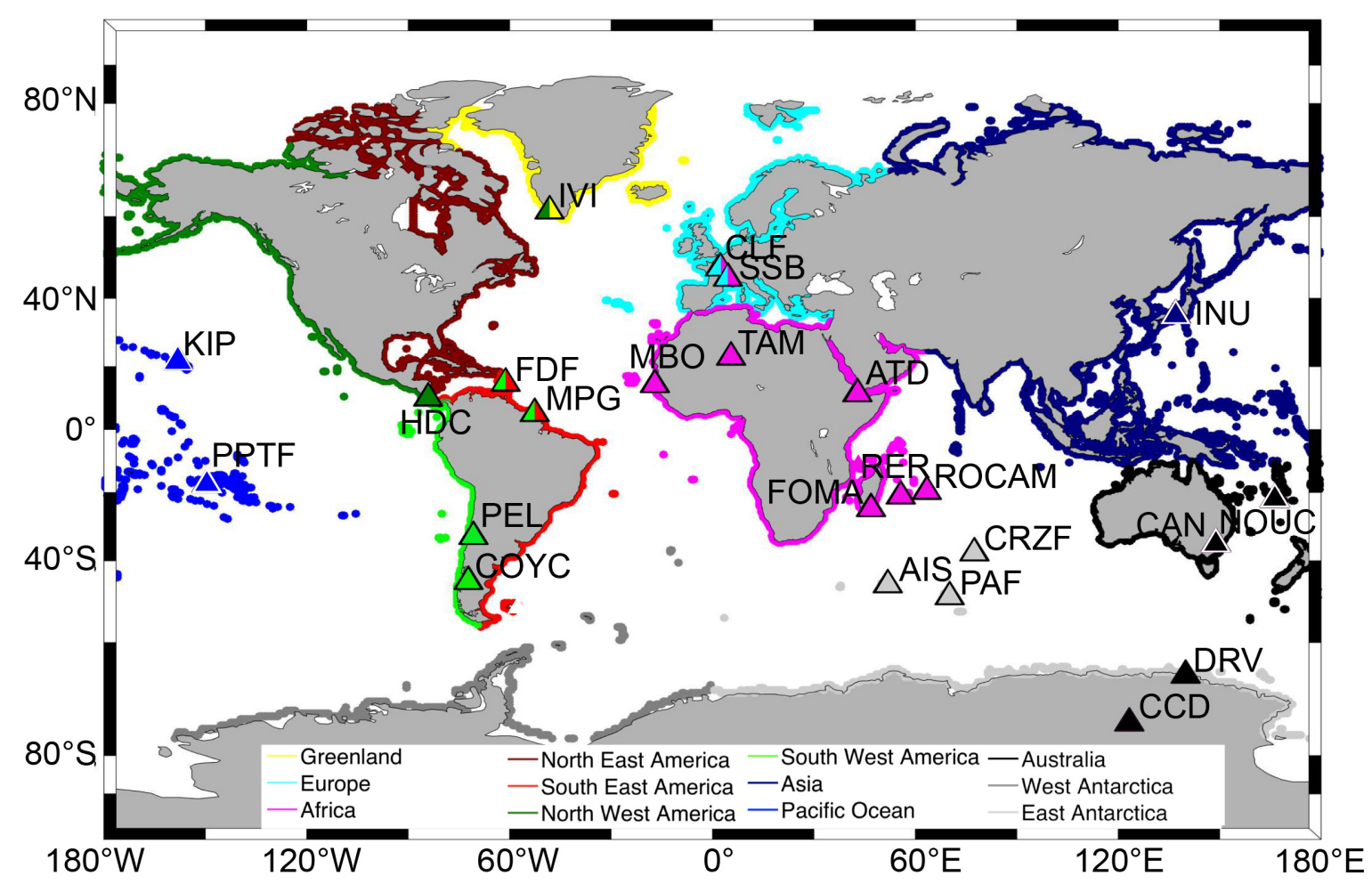

Figure 5. Map showing the 12 chosen source subregions (dots) and the 24 seismic stations (triangles), whose colour indicates the dominant source regions.

a remarkably good fit between synthetic and observed minimum displacement all year round. An exception is the station CAN at $0.05 \mathrm{~Hz}$ (Fig. 6c), for which the synthetic minimum displacement shows a systematic larger amplitude than the observed one. The same discrepancy at $0.05 \mathrm{~Hz}$ at CAN is also observed in 2017 (see Appendix A). In Supporting Information Figs S9 and S10, we investigate the frequency dependence of the effective fitting parameter. We observe that the parameter $\gamma$ is weakly frequency dependent at the major part of the stations. In a few cases, the effective fitting parameter varies with frequency (e.g. stations AIS, NOUC), although the misfit does not vary significantly around the minimum value. As a consequence, the observed overestimation at the station CAN at $0.05 \mathrm{~Hz}$ cannot be explained by our assumption of a constant effective fitting parameter.

To investigate this discrepancy between observations and synthetics at $0.05 \mathrm{~Hz}$ at the station CAN, we let the effective fitting parameter $\gamma$ vary over macro source areas of $500 \mathrm{~km}$ and we use simulated annealing to find the local effective fitting parameters that allow a better fit. By iterating over source points, each parameter $\gamma$ is slightly modified, and changes are accepted if they improve the fit. If the fit worsens, changes are still accepted with decreasing probability for increasing iteration number. The extension of the macro areas, each of which include about 100 source locations, is chosen to reduce the number of parameters and thus the computational time. To resolve detailed local changes of the effective fitting parameter $\gamma$, we minimize the L2 norm between data and synthetics.

We allow the local effective fitting parameter to vary symmetrically around the initial constant value used in the previous simulations, that is $\gamma=8$ for the station CAN (see Fig. 3 and Supporting Information Table S1). Fig. 8(a) shows the RMS minimum displacement obtained for varying the fitting parameter (final model, black) compared to the RMS minimum displacement obtained with a constant effective fitting parameter (initial model, red) and the observed RMS minimum displacement (blue), all at $0.05 \mathrm{~Hz}$. The histograms of the residuals between data and synthetics at $0.05 \mathrm{~Hz}$ computed at each time step (Fig. 8b) shows that the final model is much closer to the observations (histogram with empty black bars) than the initial model (histogram with light blue bars). The local effective fitting parameter that allows us to obtain the final model reveals a clear spatial pattern, as shown in Fig. 8(c). With respect to the starting value $(\gamma=8)$, the amplitude of the effective fitting parameter drops on the south-western side of Australia and around New Zealand, it increases on the northeastern side of Australia and remains unchanged in the Philippine Sea and around Indonesia. Possible causes for this pattern are local structure effects (bathymetry, sediments) and propagation effects (heterogeneities) or other factors in the actual source amplitude that our model does not take into account. For example, we observe that the region where the effective fitting parameter is higher than average (yellow dots in Fig. 8c) correlate well with the area of the southwestern Pacific Ocean where tropical cyclones develop. Underestimation of the ECMWF wind forcing in high wind conditions (Pineau-Guillou et al. 2018) (e.g. tropical cyclones) can lead to errors in the ocean wave height (see Supporting Information Fig. S1 1 and Rascle \& Ardhuin 2013). This can result in an underestimation of the source amplitude (Gualtieri et al. 2018) in this region, which would justify the need for a higher effective fitting parameter in our modelling.

\section{DISCUSSION AND CONCLUSIONS}

In this paper, we showed that our understanding of the generation theory of primary microseisms, combined with a state-of-the-art ocean wave model, allows us to model the amplitude of the spectrum of primary microseisms successfully at worldwide-located seismic stations and for varying time. 
(a)

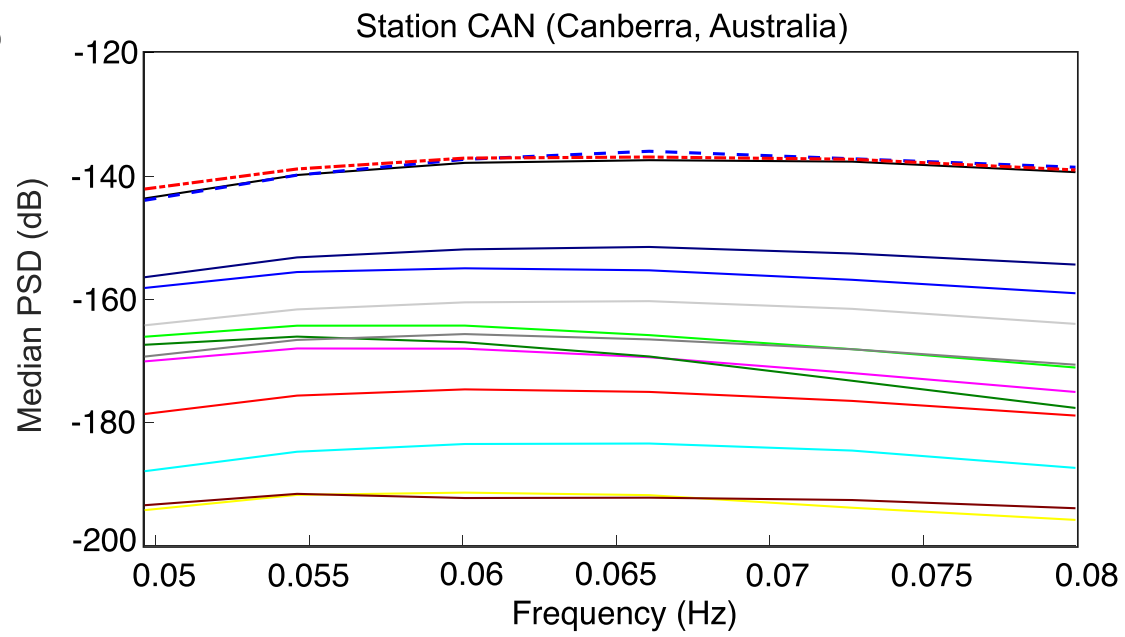

(b)

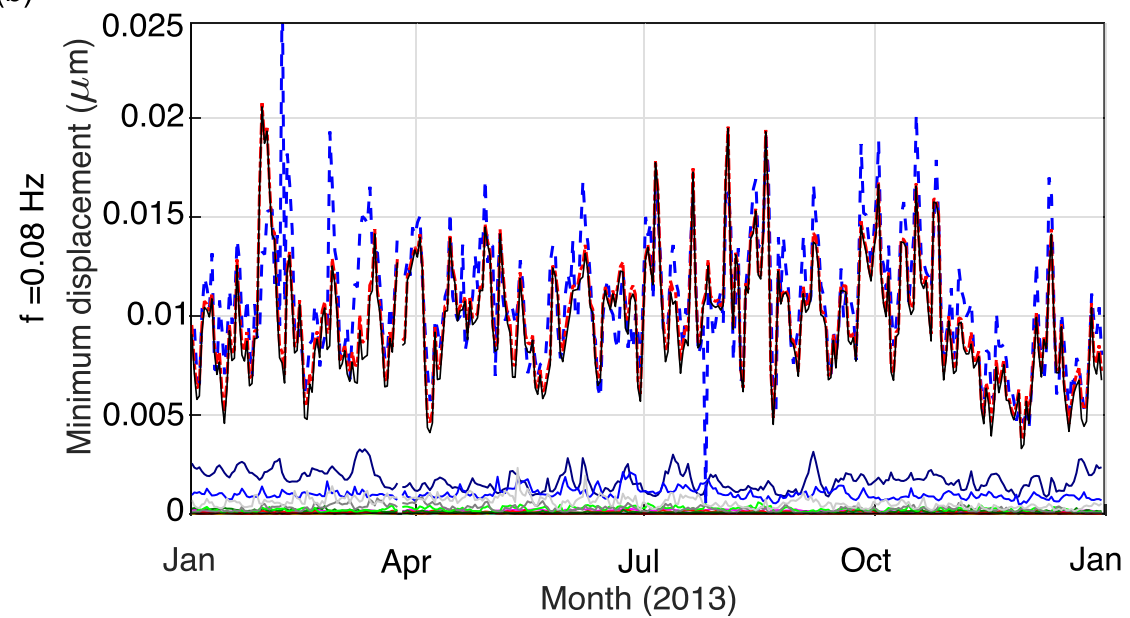

(c)

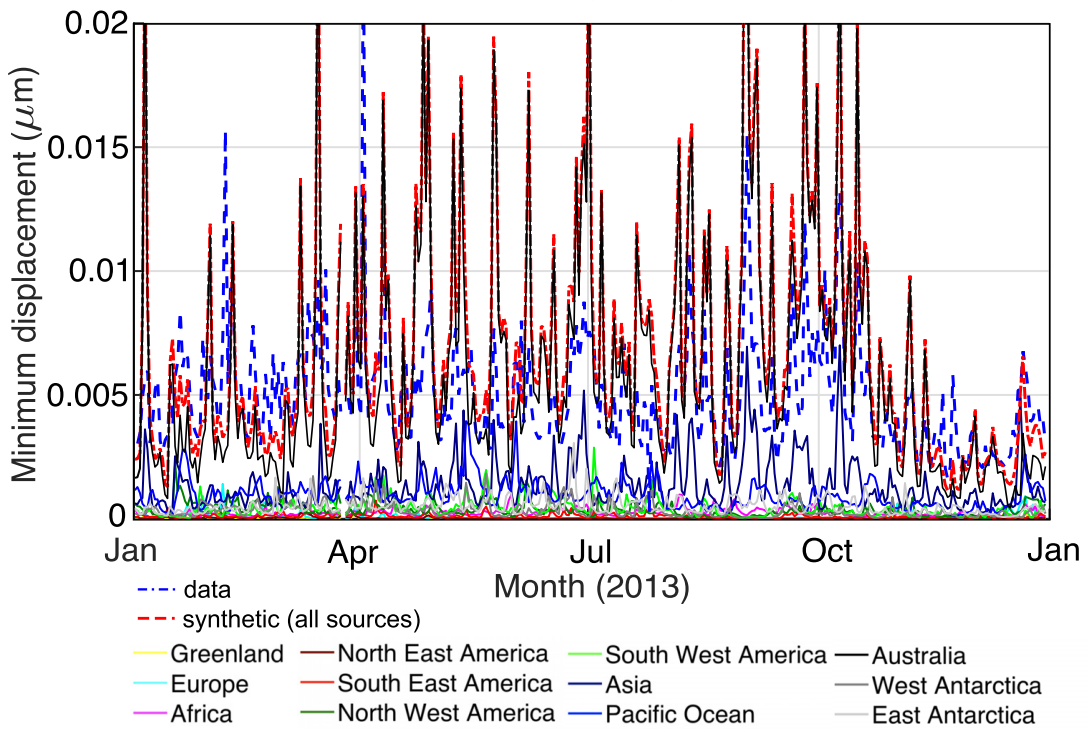

Figure 6. (a) Median PSD over 2013 and RMS minimum displacement at the station CAN (Canberra, Australia) at (b) $0.08 \mathrm{~Hz}$ and (c) $0.05 \mathrm{~Hz}$. Solid coloured lines are referred to synthetic spectra computed considering only sources in a given subregion (see Fig. 5 for the definition of the different subregions). The red dashed line represents the synthetic spectra computed considering sources at the global scale, while the blue dashed line represents data. The legend on the bottom of the figure applies to the three panels. An enlarged version of panels (b) and (c) is shown in Supporting Information Figs S5 and S6, respectively.

The pressure source PSD of primary microseisms varies with season, notably in the Northern Hemisphere. This seasonality is reflected in the seasonality of the recorded displacement as a function of time. The major part of the stations is sensitive to sources located in adjacent subregions, while some of the stations also need source regions located far away to explain the PSD of primary microseisms. 
(a)

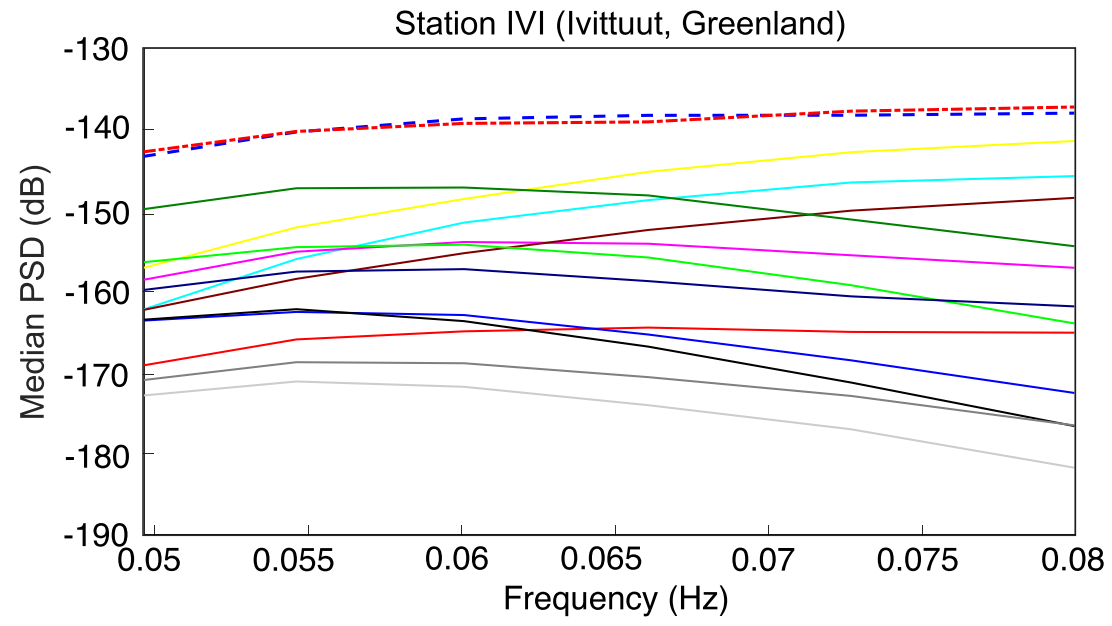

(b)

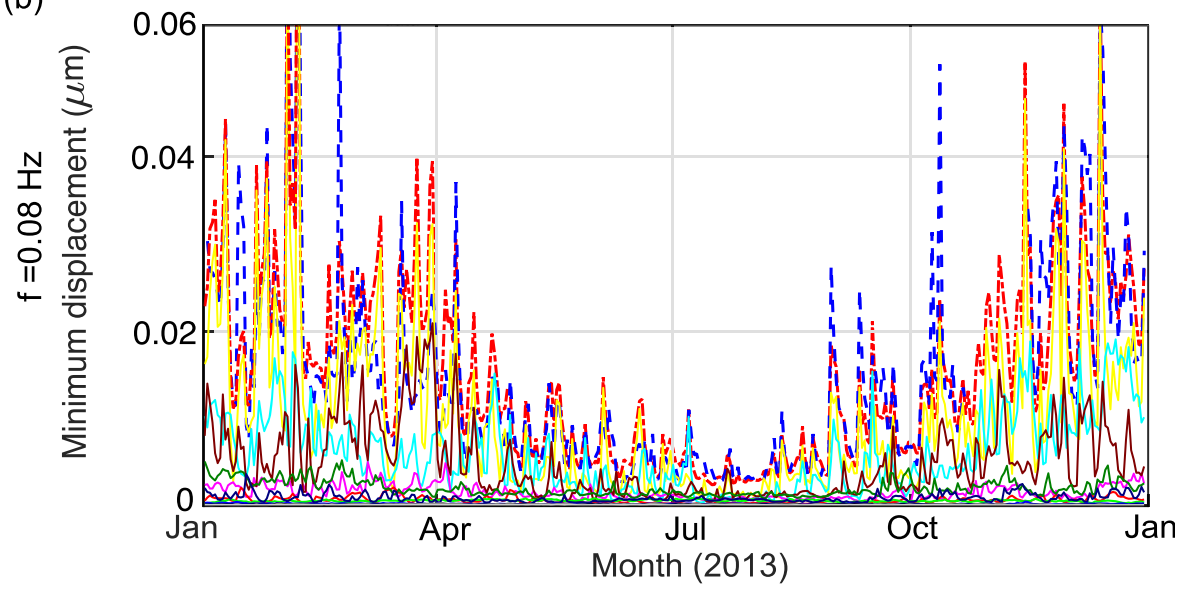

(c)

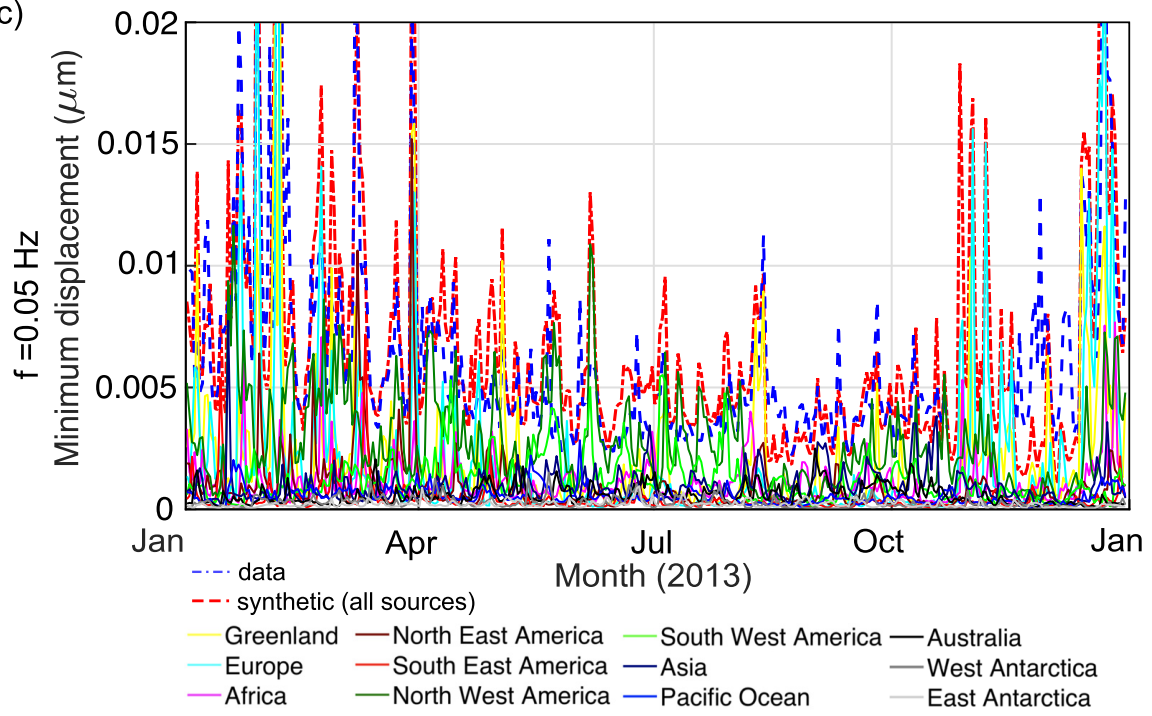

Figure 7. (a) Median PSD over 2013 and RMS minimum displacement at the station IVI (Ivittuut, Greenland) at (b) $0.08 \mathrm{~Hz}$ and (c) $0.05 \mathrm{~Hz}$. Solid coloured lines are referred to synthetic spectra computed considering only sources in a given subregion (see Fig. 5 for the definition of the different subregions). The red dashed line represents the synthetic spectra computed considering sources at the global scale, while the blue dashed line represents data. The legend on the bottom of the figure applies to the three panels. An enlarged version of panels (b) and (c) is shown in Supporting Information Figs S7 and S8, respectively.

For example, the PSD at the station IVI can be explained by sources situated around Greenland at high frequency $(f>0.06 \mathrm{~Hz})$, while they require sources on the western coasts of North America to explain the data at low frequency $(f<0.06 \mathrm{~Hz})$. The east coast of
North America, the closest coast moving west from IVI, gives a negligible contribution to the actual noise level (see Fig. 7a). The same behaviour is observed at the stations FDF and MPG, with dominant sources on the eastern coasts of South America at high 


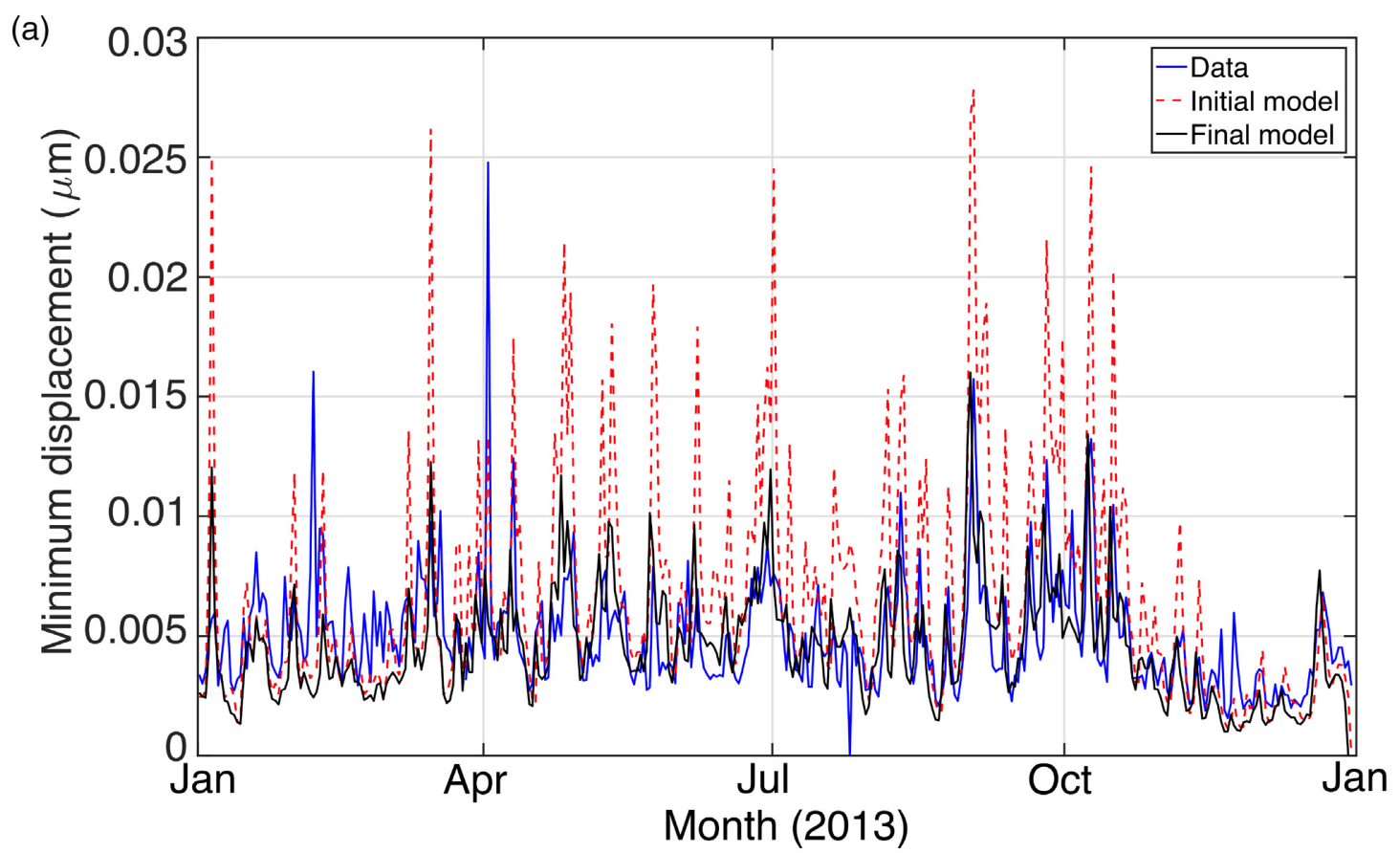

(b)

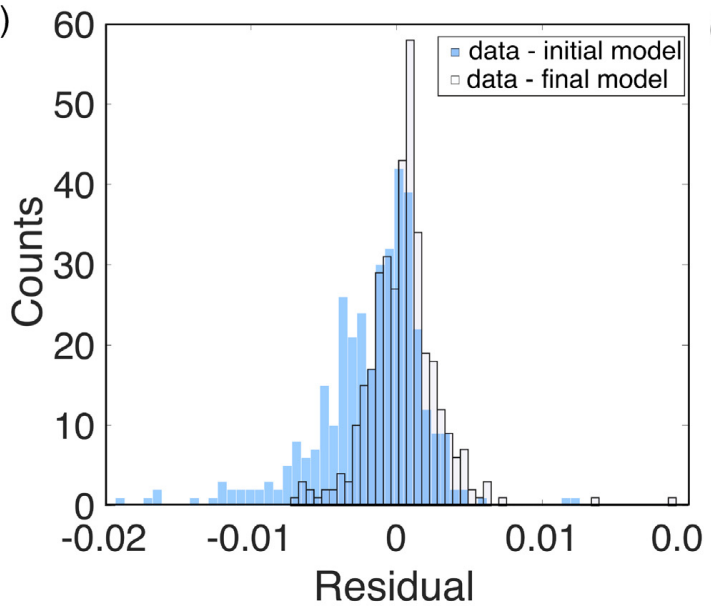

(c)

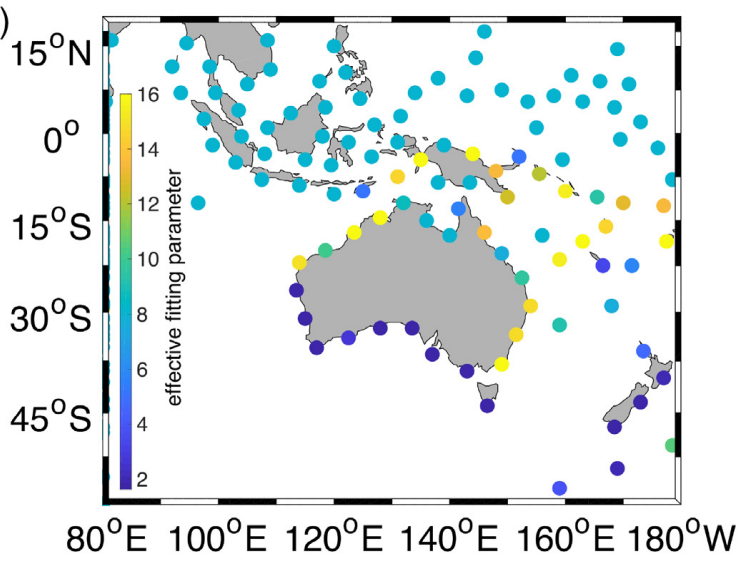

Figure 8. (a) Observed (blue) RMS minimum displacement at $0.05 \mathrm{~Hz}$ recorded at the station CAN compared to the corresponding synthetic obtained with a constant effective fitting parameter $s=8$ (red) and to the synthetic obtained varying the effective fitting parameters over macro areas (black). (b) Histogram of the residuals between data and synthetics (as shown in panel a) computed with a constant effective fitting parameter (light blue) and a varying effective fitting parameter (black contours). (c) Map showing the effective fitting parameter computed over macro areas of $500 \mathrm{~km}$.

frequency and on the western coasts of South America at low frequency. The much closer eastern coasts of North America give a negligible contribution (see Supporting Information Fig. S4).

One key aspect of the generation of primary microseisms is the slope of the bathymetry in shallow water, where ocean waves propagate. In our modelling, the effect of the slope in shallow water is included in the effective fitting parameter $\gamma$ (see Fig. 3 and Supporting Information Table S1), which is assessed for each station by minimizing the $\mathrm{L} 1$ norm between data and synthetics. This parameter also includes source site effects [e.g. sediments (Gualtieri et al. 2015; Koper \& Burlacu 2015), fine-scale seafloor roughness] and 3-D propagation effects (e.g. scattering at the ocean-continent boundary, focusing and defocusing at heterogeneities), which are not taken into account in our 1-D modelling. The effective fitting parameter estimated for each station is time independent. The same values can be used to compute synthetic PSDs of primary microseisms during other periods of time (Appendix A). A simple test for sources around Australia recorded at the station CAN at $0.05 \mathrm{~Hz}-$ taken as a case study because of the systematic discrepancy between data and modelling - revealed that local variations of the effective fitting parameter can improve the fit between data and synthetics.

\section{ACKNOWLEDGEMENTS}

We thank the GEOSCOPE Observatory and the Incorporated Research Institutions for Seismology (IRIS) for providing openly available seismic data. The output of the ocean wave model can be found at ftp://ftp.ifremer.fr/ifremer/ww3/HINDCAST. LG acknowledges support from Princeton University and King Abdullah University of Science and Technology. ES and FA acknowledge support through the ANR Project MIMOSA under Grant ANR-14-CE01-0012. CJ 
acknowledges support through the Cluster of Excellence 'CliSAP' (EXC177), Universität Hamburg, funded through the German Science Foundation (DFG). CJ and $\mathrm{CH}$ acknowledge support by the Emmy Noether program (HA7019/1-1) of the German Research Foundation (DFG). We also wish to acknowledge useful discussions during the TIDES Training Schools, supported by the COST Action ES1401 (European Cooperation in Science and Technology). We thank two anonymous reviewers for their constructive comments that helped to improve the manuscript.

\section{REFERENCES}

Ardhuin, F., 2018. Large-scale forces under surface gravity waves at a wavy bottom: a mechanism for the generation of primary microseisms, Geophys. Res. Lett., 45(16), 8173-8181.

Ardhuin, F., Rawat, A. \& Aucan, J., 2014. A numerical model for free infragravity waves: definition and validation at regional and global scales, Ocean Modelling, 77, 20-32.

Ardhuin, F., Gualtieri, L. \& Stutzmann, E., 2015. How ocean waves rock the Earth: two mechanisms explain microseisms with periods 3 to $300 \mathrm{~s}$, Geophys. Res. Lett., 42(3), 765-772.

Ardhuin, F., Gualtieri, L. \& Stutzmann, E., 2019. Physics of ambient noise generation by ocean waves, in Seismic Ambient Noise, chap. 3, pp. 69108, eds Nakata, N., Gualtieri, L. \& Fichtner, A., Cambridge University Press.

Aster, R.C., McNamara, D.E. \& Bromirski, P.D., 2008. Multidecadal climate-induced variability in microseisms, Seismol. Res. Lett., 79(2), 194-202.

Cessaro, R.K., 1994. Sources of primary and secondary microseisms, Bull. seism. Soc. Am., 84(1), 142-148.

Davy, C., Stutzmann, E., Barruol, G., Fontaine, F.R. \& Schimmel, M., 2015. Sources of secondary microseisms in the Indian Ocean, Geophys. J. Int., 202(2), 1180-1189.

Durek, J.J. \& Ekström, G., 1996. A radial model of anelasticity consistent with long-period surface-wave attenuation, Bull. seism. Soc. Am., 86(1A), $144-158$.

Dziewonski, A.M. \& Anderson, D.L., 1981. Preliminary reference Earth model, Phys. Earth planet. Inter., 25(4), 297-356.

Friedrich, A., Krüger, F. \& Klinge, K., 1998. Ocean-generated microseismic noise located with the Gräfenberg array, J. Seismol., 2(1), 47-64.

Gal, M., Reading, A., Rawlinson, N. \& Schulte-Pelkum, V., 2018. Matched field processing of 3 component seismic array data applied to Rayleigh and Love microseisms, J. Geophys. Res., 123, 6781-6789.

Grob, M., Maggi, A. \& Stutzmann, E., 2011. Observations of the seasonality of the Antarctic microseismic signal, and its association to sea ice variability, Geophys. Res. Lett., 38(11), L11302.

Gualtieri, L., Stutzmann, E., Capdeville, Y., Ardhuin, F., Schimmel, M., Mangeney, A. \& Morelli, A., 2013. Modelling secondary microseismic noise by normal mode summation, Geophys. J. Int., 193(3), 1732-1745.

Gualtieri, L., Stutzmann, E., Capdeville, Y., Farra, V., Mangeney, A. \& Morelli, A., 2015. On the shaping factors of the secondary microseismic wavefield, J. geophys. Res., 120(9), 6241-6262.

Gualtieri, L., Camargo, S.J., Pascale, S., Pons, F.M. \& Ekström, G., 2018. The persistent signature of tropical cyclones in ambient seismic noise, Earth planet. Sci. Lett., 484, 287-294.

Hasselmann, K., 1963. A statistical analysis of the generation of microseisms, Rev. Geophys., 1(2), 177-210.

Haubrich, R.A. \& McCamy, K., 1969. Microseisms: coastal and pelagic sources, Rev. Geophys., 7(3), 539-571.

Haubrich, R.A., Munk, W.H. \& Snodgrass, F.E., 1963. Comparative spectra of microseisms and swell, Bull. seism. Soc. Am., 47, 111-127.

Juretzek, C. \& Hadziioannou, C., 2016. Where do ocean microseisms come from? A study of Love-to-Rayleigh wave ratios, J. geophys. Res., 121(9), 6741-6756.

Juretzek, C. \& Hadziioannou, C., 2017. Linking source region and ocean wave parameters with the observed primary microseismic noise, Geophys. J. Int., 211(3), 1640-1654.
Kanamori, H. \& Given, J.W., 1981. Use of long-period surface waves for rapid determination of earthquake-source parameters, Phys. Earth planet. Int., 27(1), 8-31.

Koper, K.D. \& Burlacu, R., 2015. The fine structure of double-frequency microseisms recorded by seismometers in North America, J. geophys. Res., 120(3), 1677-1691.

Koper, K.D. \& de Foy, B., 2008. Seasonal anisotropy in short-period seismic noise recorded in South Asia, Bull. seism. Soc. Am., 98(6), 3033-3045.

Longuet-Higgins, M.S., 1950. A theory of the origin of microseisms, Phil. Trans. R. Soc. A, 243(857), 1-35.

Nishida, K., Kawakatsu, H., Fukao, Y. \& Obara, K., 2008. Background Love and Rayleigh waves simultaneously generated at the Pacific Ocean floors, Geophys. Res. Lett., 35(16), L16307, doi:10.1029/2008GL034753.

Pineau-Guillou, L., Ardhuin, F., Bouin, M.-N., Redelsperger, J.-L., Chapron, B., Bidlot, J.-R. \& Quilfen, Y., 2018. Strong winds in a coupled waveatmosphere model during a North Atlantic storm event: evaluation against observations, Q. J. R. Meteorol. Soc., 144(711), 317-332.

Rascle, N. \& Ardhuin, F., 2013. A global wave parameter database for geophysical applications. Part 2: Model validation with improved source term parameterization, Ocean Modelling, 70, 174-188.

Saito, T., 2010. Love-wave excitation due to the interaction between a propagating ocean wave and the sea-bottom topography, Geophys. J. Int., 182(3), 1515-1523.

Schimmel, M., Stutzmann, E., Ardhuin, F. \& Gallart, J., 2011. Polarized Earth's ambient microseismic noise, Geoch. Geophys. Geosyst., 12(7, Q07014).

Stutzmann, E., Schimmel, M., Patau, G. \& Maggi, A., 2009. Global climate imprint on seismic noise, Geochem. Geophys. Geosyst., 10(11), Q11004.

Stutzmann, E., Ardhuin, F., Schimmel, M., Mangeney, A. \& Patau, G., 2012. Modelling long-term seismic noise in various environments, Geophys. J. Int., 191(2), 707-722.

Ziane, D. \& Hadziioannou, C., 2019. The contribution of multiple scattering to Love wave generation in the secondary microseism, Geophys. J. Int., 217(2), 1108-1122.

\section{SUPPORTING INFORMATION}

Supplementary data are available at $G J I$ online.

Figure S1. Observed (blue dashed line) and synthetic PSD (in $\mathrm{dB}$ with respect to $1 \mathrm{~m}^{2} \mathrm{~Hz}^{-1}$ ) computed considering sources at the global scale (red dashed line). Solid coloured lines refer to synthetic spectra computed considering only sources in a given subregion. Source subregions are shown in Fig. 5 in the main paper. The observed PSD at these stations can be explained by sources along the west coast of South America (top panels), around islands in the Pacific Ocean (middle panels), and along the west coast of North America (bottom panel).

Figure S2. Observed (blue dashed line) and synthetic PSD (in dB with respect to $1 \mathrm{~m}^{2} \mathrm{~Hz}^{-1}$ ) computed considering sources at the global scale (red dashed line). Solid coloured lines refer to synthetic spectra computed considering only sources in a given subregion. Source subregions are shown in Fig. 5 in the main paper. The observed PSD at these stations can be explained by sources along the coasts of Asia (top, left column), Australia (top, right) and East Antarctica (middle and bottom panels).

Figure S3. Observed (blue dashed line) and synthetic PSD (in $\mathrm{dB}$ with respect to $1 \mathrm{~m}^{2} \mathrm{~Hz}^{-1}$ ) computed considering sources at the global scale (red dashed line). Solid coloured lines refer to synthetic spectra computed considering only sources in a given subregion. Source subregions are shown in Fig. 5 in the main paper. The observed PSD at these stations can be explained by sources along the coasts of Africa.

Figure S4. Observed (blue dashed line) and synthetic PSD (in $\mathrm{dB}$ with respect to $1 \mathrm{~m}^{2} \mathrm{~Hz}^{-1}$ ) computed considering sources at the 
global scale (red dashed line). Solid coloured lines refer to synthetic spectra computed considering only sources in a given subregion. Source subregions are shown in Fig. 5 in the main paper. The observed PSD at these stations can be explained by a two dominant source regions for varying frequency (top four panels) or by sources around Australia (bottom panels).

Figure S5. Enlarged version of Fig. 6(b).

Figure S6. Enlarged version of Fig. 6(c).

Figure S7. Enlarged version of Fig. 7(b).

Figure S8. Enlarged version of Fig. 7(c).

Figure S9. L1-norm misfit between data and synthetics in the frequency band of primary microseisms $(0.05-0.08 \mathrm{~Hz}$, blue $)$ compared to the L1-norm misfit in two narrow frequency bands: $0.05-0.06 \mathrm{~Hz}$ (red) and $0.07-0.08 \mathrm{~Hz}$ (black). Each panel corresponds to a seismic station (see Fig. 1 for station location).

Figure S10. (continued).

Figure S11. Normalized root mean square error (NRMSE) for the modelled significant wave heights $H_{\mathrm{s}}$ in 2013, against data from Jason-1, Jason-2 and Envisat altimeters.

Table S1. Coordinates of the Geoscope seismic stations used in this study. For each station, the effective fitting parameter $\gamma$ obtained minimizing the misfit between data and synthetics is given.

Please note: Oxford University Press is not responsible for the content or functionality of any supporting materials supplied by the authors. Any queries (other than missing material) should be directed to the corresponding author for the paper.

\section{APPENDIX A: MODELLING PRIMARY MICROSEISMS RECORDED IN 2017}

To evaluate whether our results vary over time and assess the robustness of the effective fitting parameter, we compute synthetic PSDs in 2017 using the same effective fitting parameters estimated using data in 2013 (Supporting Information Table S1 and Fig. 3).

Fig. A1 shows the comparison between data (blue) and synthetics (red) at eight stations of the Geoscope network. The locations of the stations are shown in Fig. 4. Fig. A1(a) shows the time-series of RMS minimum displacement integrated between 0.05 and $0.08 \mathrm{~Hz}$. As in Fig. 4(c) for 2013, the time-series in 2017 in Fig. A1(a) are plotted as a function of station latitude ( $y$-axis). The time evolution and the strongest peaks in the data are well reproduced by the synthetics. Like in 2013, we observe a pronounced seasonality at stations in the Northern Hemisphere.

Fig. A1(b) shows the PSD (in $\mathrm{dB}$ with respect to $1 \mathrm{~m}^{2} \mathrm{~Hz}^{-1}$ ) as the median value of the PSDs computed every $3 \mathrm{hr}$ in 2017 and as a function of frequency. Data are in blue and synthetics are in red. The overall shape and amplitude of the PSD are well reconstructed at all stations, with a fit within a few $\mathrm{dB}$. We recall that the same effective fitting parameters found in Section 2 for 2013 have been used to compute synthetics in 2017.

We also investigate the RMS of the displacement at the station CAN in 2017 for varying frequency. Similarly to 2013 (Figs $6 \mathrm{~b}$ and c), we find that the fit between data and synthetics is particularly
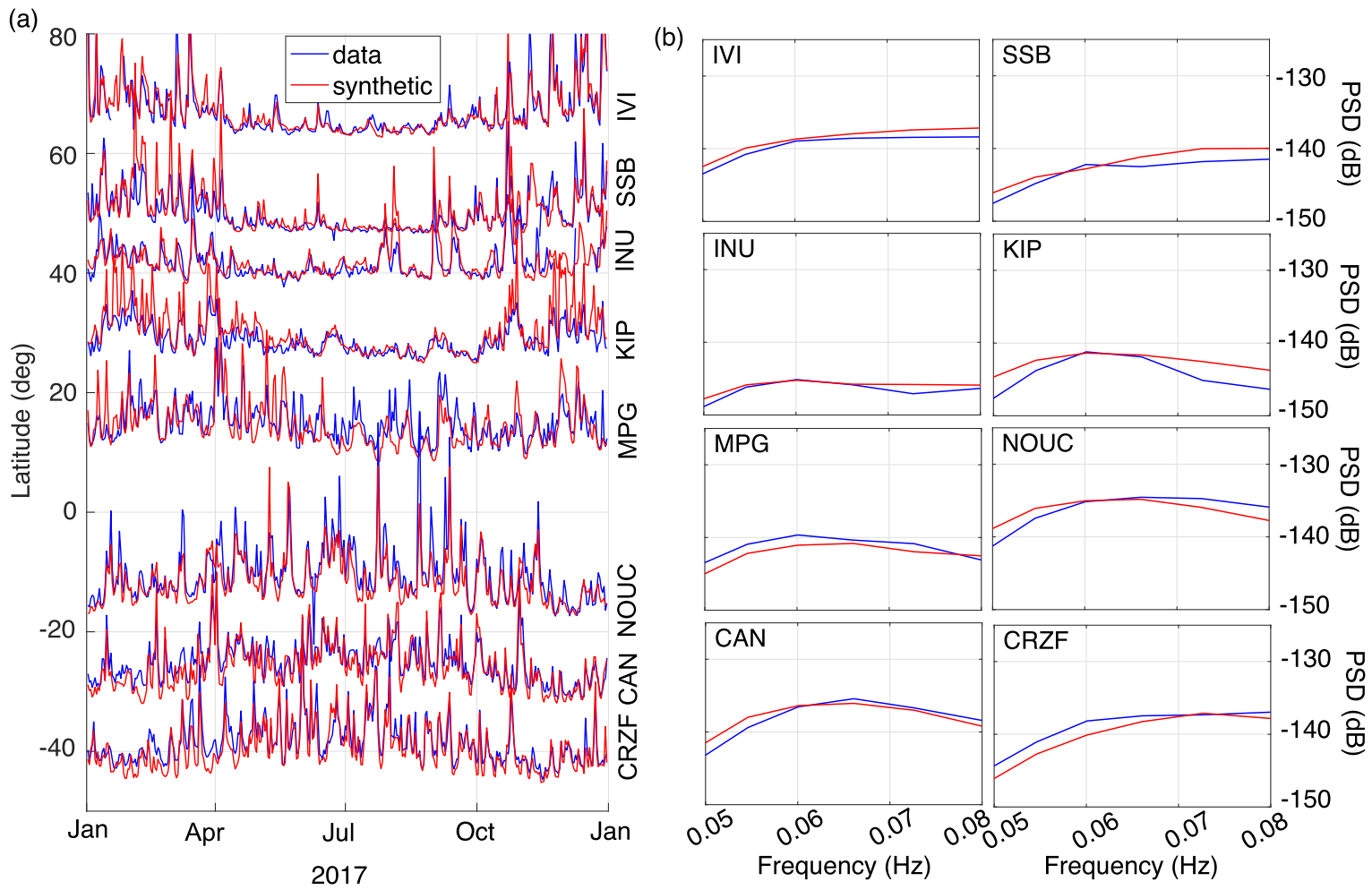

Figure A1. (a) Observed (blue) and synthetic (red) seismic displacements in 2017 as a function of time ( $x$-axis). The time-series are normalized with respect to the standard deviation at each station and sorted by station latitude ( $y$-axis). (b) Observed (blue) and synthetic (red) seismic displacement PSDs (in dB with respect to $1 \mathrm{~m}^{2} \mathrm{~Hz}^{-1}$ ) of primary microseisms in 2017 as a function of frequency. Synthetics have been computed using the same empirical fitting parameters $\gamma$ found minimizing the misfit between data and synthetics in 2013 (Fig. 3 and Supporting Information Table S1). The locations of the seismic stations are shown in Figs 4(a) and (b). 
good at $f=0.08 \mathrm{~Hz}$ (Fig. A2a), while at $f=0.05 \mathrm{~Hz}$ (Fig. A2b) the modelled time-series (dashed red line) shows larger amplitudes than observations (blue dashed line). This persistent overestimation could indicate a recurrent overestimation of the source amplitude in this region (e.g. associated with tropical cyclones, see Section 3.4) or to features that have not been taken into account in our modelling (e.g. sediments at the source).

(a)

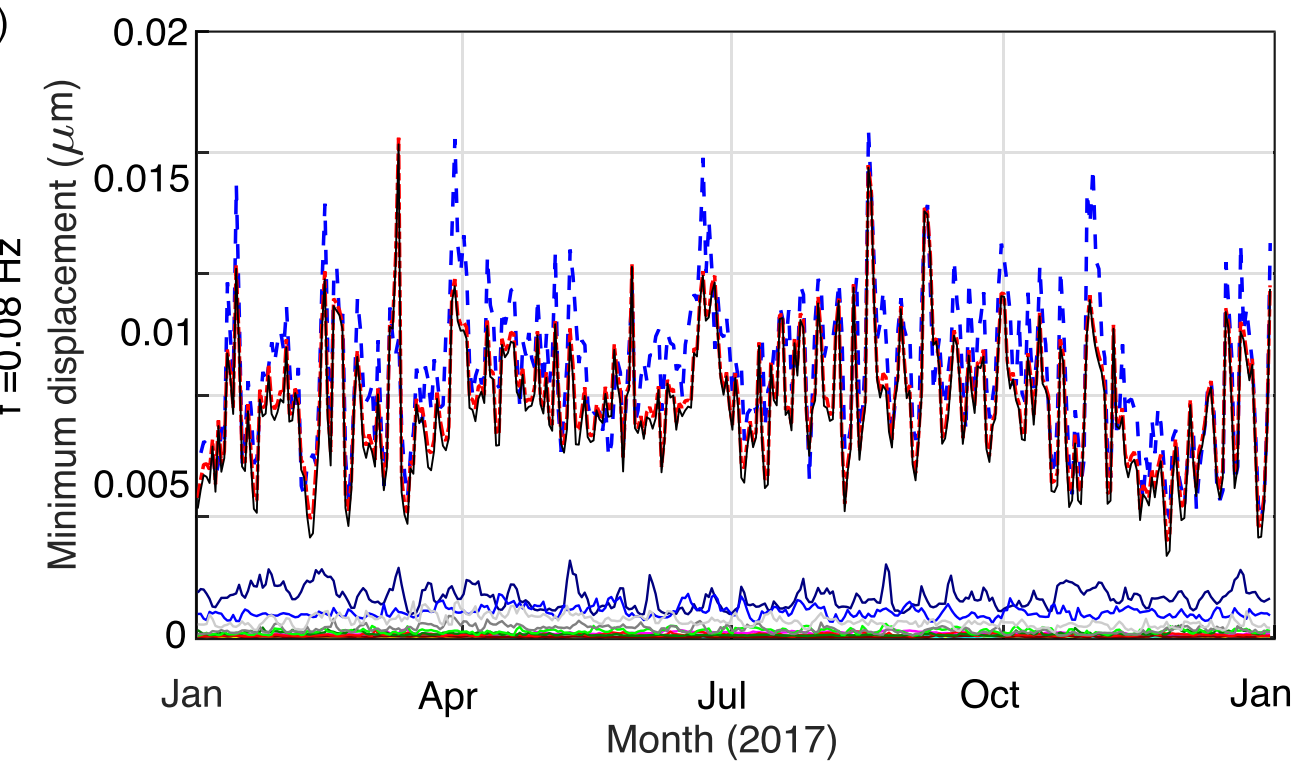

(b)

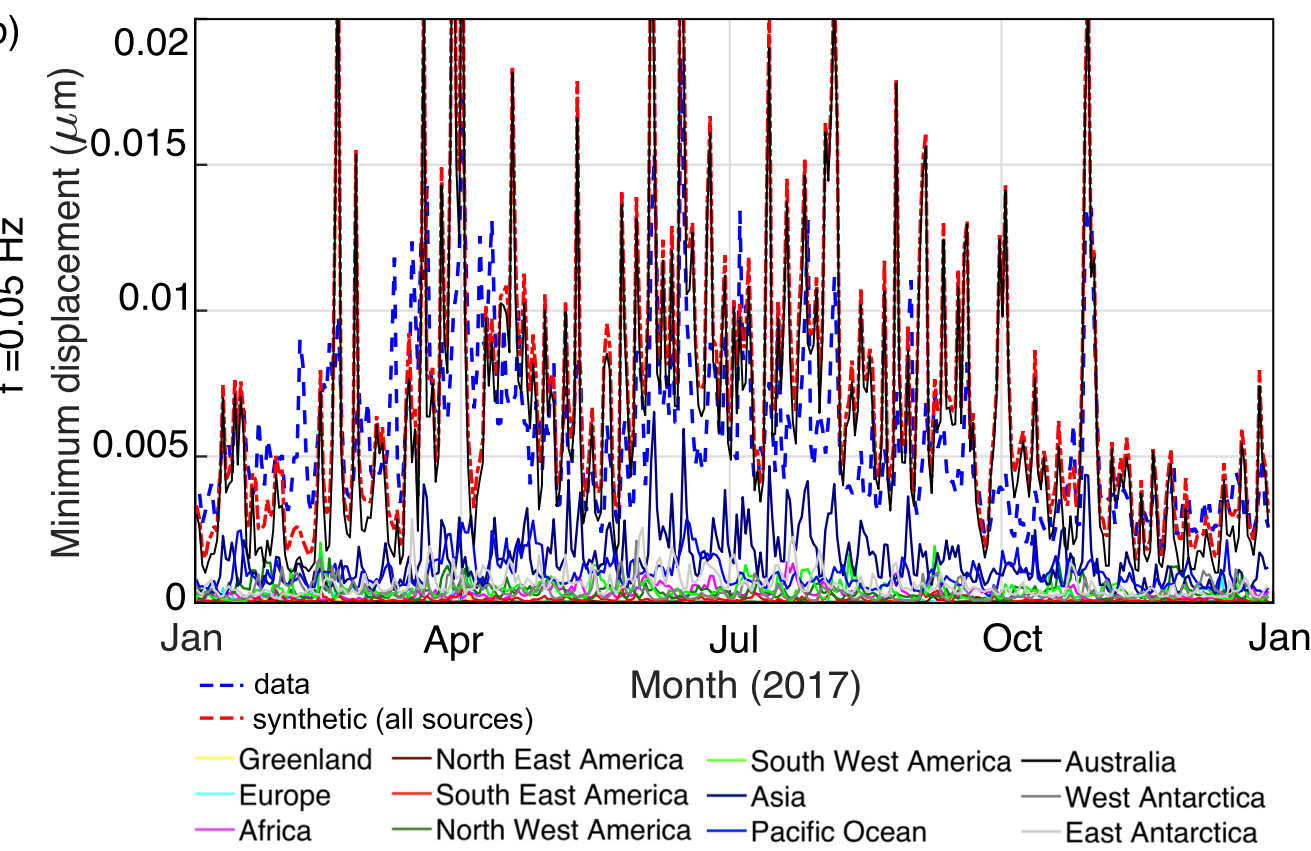

Figure A2. RMS minimum displacement at the station CAN (Canberra, Australia) in 2017 at (a) $0.08 \mathrm{~Hz}$ and (b) $0.05 \mathrm{~Hz}$. Solid coloured lines denote synthetic spectra computed considering only sources in a given subregion (see Fig. 5 for the definition of the different subregions). The red dashed line represents the synthetic spectra computed considering sources at the global scale, while the blue dashed line represents data. 